\title{
Antropologia e água: perspectivas plurais
}

\section{Carla Teixeira e Maria Manuel Quintela}

\section{Q OpenEdition}

\section{Journals}

\section{Edição electrónica}

URL: http://journals.openedition.org/aa/1081

DOI: 10.4000/aa.1081

ISSN: 2357-738X

\section{Editora}

Programa de Pós-Graduação em Antropologia Social (UnB)

\section{Edição impressa}

Data de publição: 1 dezembro 2011

Paginação: 9-22

ISSN: 0102-4302

\section{Refêrencia eletrónica}

Carla Teixeira e Maria Manuel Quintela, «Antropologia e água: perspectivas plurais», Anuário

Antropológico [Online], v.36 n.1 | 2011, posto online no dia 19 novembro 2015, consultado o 28 abril 2021. URL: http://journals.openedition.org/aa/1081 ; DOI: https://doi.org/10.4000/aa.1081

\section{(c) (1) (8)}

Anuário Antropológico is licensed under a Creative Commons Atribuição-Uso Não-Comercial-Proibição de realização de Obras Derivadas 4.0 International. 


\section{Antropologia e água: perspectivas plurais}

Carla Teixeira

Universidade de Brasília

Maria Manuel Quintela

Escola Superior de Enfermagem de Lisboa

A relação entre a água e os humanos é universal na vida social, sem água não há vida e a humanidade não sobrevive sem ela. Estas são premissas do senso comum e das ciências biológicas. A forma como esta relação é estabelecida e o sentido particular que lhe é atribuído em cada contexto geográfico, etnográfico e histórico são já objectos de atenção antropológica. Os estudos produzidos apresentam uma grande diversidade de perspectivas teóricas de acordo com o eixo de análise escolhido, as áreas disciplinares e com o momento social histórico e político vivido das transformações ocorridas na relação entre humanos e este elemento natural (Hipocrates, 1996). Com a disciplinarização da ciência e da química em particular, o líquido água transformou-se em H20, concepções que conviveram e convivem em simultâneo com noções "não científicas" da água e das águas, classificadas e hierarquizadas de acordo com critérios sensoriais (Strang, 2004, 2006), do domínio da experiência e do contacto com este elemento, denominado e percebido como líquido, substância, virtude, remédio, medicamento (Durand, 2003; Quintela, 2001, 2004; Marras, 2004), em todos os seus estados materializáveis (Martel, 1989). Convivem, também, com a atenção dada aos objectos que se produziram para este primeiro nível de contacto, como mediadores desta primeira relação íntima com o corpo, como banheiras, chuveiros e bidés nas suas diversas formas de uso e objectivos (Goubert, 1986; Corbin, 1986; Roche, 1997), bem como com as reflexões sobre a relação com os recursos do meio ambiente: água, rios, lagos, lagoas, mares, poças, montanhas.

Essas produções de estudos sociais, geográficos, históricos e filosóficos tiveram a água como inspiradora e pretexto para escrever sobre o imaginário produzido por ela (Bachelard, 1943) na criatividade humana (Shama, 1996), sobre o simbolismo das águas e dos rios sagrados (Eliade, 1994; Hidiroglou, 1976; Feldhauss, 1995), na produção de objectos (Goubert, 1986; Wateau, 2002) e 
como elemento civilizatório (Elias, 1976) através de práticas de higiene e regulamentos médicos (Vigarello, 1988), marcada sobretudo a partir do século XIX na Europa pela domesticação da água, entrou dentro das casas (Goubert, 1986). Porém, não entrou em todas as casas, nem em todos os contextos geográficos, e a simples operação de abrir uma torneira e sair um fio de água sem esforço para alguns estratos sociais significou que outros trabalhavam para construir todo um complexo hidráulico de abastecimento de águas, sobretudo em cidades e vilas (Denise Sant'Ana, 1997).

A ilusão de um líquido fácil não fez esquecer antropólogos e etnológos de estudarem este elemento como um recurso escasso em alguns contextos geográficos, como é o caso dos desertos e dos oásis (Ftaïta, 2006; Stern, 2003), bem como da sua regulação em sociedades e comunidades que se organizam socialmente em torno dela e nas quais a gestão da água é fonte de conflitos e de consensos (Wateau, 2000, 2010; Durand, 2003) - pondo em discussão as próprias noções de escassez e abundância - como são as situações das regiões onde foram construídas barragens, ou seja, "dar” água e "afogar” aldeias através de formas políticas de produção de energia e discussão de políticas públicas (Santos, 2003; Wateau, 2010; Saraiva, 2007; Durand, 2003). Essas reflexões vão desde a governança à sustentabilidade da água em níveis local, regional e global e têm sido objecto de estudo na última década por parte de antropólogos (Orlove \& Caton, 2010; Kaplan, 2007, 2010) e outros cientistas sociais (Schneier-Madanes, 2010), as preocupações e os estudos tendo se desenvolvido, sobretudo, na perspectiva de políticas públicas de gestão da água, através do eixo analítico do conflito, do consenso, da escassez e da abundância. Não podemos analisar a focalização destas perspectivas na última década descontextualizandoas da produção de políticas globais sobre a água de o facto de 2005-2015 ter sido eleito pela Organização Nações Unidas como o decénio da água - Água, Fonte de Vida. Neste documento, a ONU tem como objectivo tornar acessível a água a todos os povos e em condições de potabilidade. Aquilo que pudemos constatar ao analisar a literatura antropológica produzida na primeira década do século XXI é exactamente a ênfase dada a estas temáticas, sobretudo às questões de "governança", "governamentalidade" e "sustentabilidade" na segunda metade dessa década (Orlove \& Caton, 2010).

São alguns os periódicos que têm a água como objecto temático e apresentam etnografias a partir dela. Destacamos aqui "Os usos sociais da água”, da revista portuguesa Etnográfica, coordenada por Cristiana Bastos (2003), em que temos desde culturas de banhos (praia e termas), consensos e conflitos até barragens. Por contextos geográficos, a obra francesa coordenada por Fabienne Wateau 
e Patrice Cressier, publicada em 2006 e intitulada Le partage de l'eau (Espagne, Portugal, Maroc). Em 2006 a revista Worlviews: global, religions, Culture and Ecology editou um número organizado por Veronica Strang que tem como seu eixo organizador a água como produtora de paisagens, de identidades e de sentidos. A American Association of Anthropology, em início de 2010, publicou dois números da Anthropology News (vol. 51) que tem a água como questão central, com os subtítulos "Water governance and management" (n. 1) e "The meaning of water" (n. 2); e em outubro deste mesmo ano, a Cultural Anthropology Virtual Issues republica cinco artigos que fizeram parte desta revista entre 1999 e 2009. Da mesma maneira, temos acesso online a projectos que tiveram a água como tema, como são, por exemplo, os casos de levantamento sobre águas portuguesas - "O novo aquilégio" ics.ul.pt (Bastos, Quintela \& Perstrelo, 2003-2006), e "Think with Water", coordenado por Verónica Strang (2010).

É ainda de destacar a edição em França de uma colectânea pluridisciplinar sobre a "gestão da água num processo de mundialização" em quatro contextos geográficos (Europa, América Latina, África e Ásia), que reúne um conjunto de 27 temas sobre a água, organizada por Graciela Schneier-Madanes, intitulada "La Mondialization de l'eau. La governance en question” (2010). Contrariamente à escassez, temos sociedades em que a abundância da água se banaliza pelos seus autóctones, mas não pelas elites que as transformam em paisagens como locais a visitar para os turistas, quer sejam as cataratas, as águas de montanha, como as dos rios, dos lagos, e ou as termais e terapêuticas, onde se desenvolvem culturas da água, destacando-se a relação entre água e lazer, que sofreu transformações sociais e históricas (Anderson \& Tabb, 2002).

Que desafios se colocam então ao estudo da relação com a água? A leitura cuidadosa dos estudos aqui referidos e dos que compõem este dossiê indica que colocarão provavelmente os mesmos desafios e dificuldades que se colocam a outros temas da antropologia: reflectir e estudar questões universais e suas transformações em cada contexto particular histórico, social e político. Deste modo, não é abrir mais um subcampo, mas sim permitir, através de estudos etnográficos, reestabelecer o diálogo com a relação entre natureza e cultura em contextos em transformação até pela ausência deste bem, quer não só quanto à sua escassez, como quanto à sua potabilidade para eliminar as ironias da água (Kaplan, 2011), tal como outras nestes mundos de contradições e assimetrias sociais.

$* * *$

Qualificar a abordagem antropológica sobre a água, como visto no panorama apresentado, implica atentar para a necessária inserção do debate em contextos 
particulares, tanto de produção de conhecimento quanto de experiência com a água. A pluralidade espaço-temporal que surge deste recorte permite vislumbrar o amplo horizonte de realizações humanas propiciadoras e propiciadas por este elemento, ao qual apenas com a química e as descobertas de Lavoisier a ciência atribuiu propriedades naturais universais.

Motivadas por este espírito e com o intuito de produzir um dossiê sobre antropologia e água, que vem a ser o primeiro organizado no âmbito dos periódicos brasileiros de antropologia, buscamos introduzir os cientistas sociais e outros leitores interessados no tema na diversidade de problemas recortados pelos antropólogos em suas investigações, com o intuito de oferecer uma aproximação à complexidade das relações sociais que têm na água seu eixo articulador, e também contribuir para a reflexão sobre a relevância da imaginação etnográfica na articulação de diversas técnicas de pesquisa neste campo. Daí a relevância de contarmos com colaboradores que realizam pesquisas em realidades etnográficas distintas, oriundos de contextos nacionais e linhagens teóricas diferenciadas, bem como de não termos definido uma indagação, teórica ou etnográfica, que unificasse as abordagens dos artigos. Assim, embora com certa concentração de autores oriundos de Brasil e Portugal, devido à localização de suas organizadoras, contamos também com a participação de pesquisadores de inserção francesa e anglo-saxã e, graças à aceitação deste desafio pelos autores aqui reunidos, logramos agrupar investigações cuja qualidade, como apresentada a seguir, articula variedade empírica e conceitual.

O primeiro artigo, seguindo ordenação alfabética, de autoria de Andréa Zhouri, Raquel Oliveira e Klemens Laschefski, "A supressão da vazante e o início do vazio: água e 'insegurança administrada' no Vale do Jequitinhonha MG”, aborda um conflito sociotécnico e normativo gerado pela construção da hidrelétrica de Urapé. Integra, assim, uma literatura que investiga os processos nos quais a necessidade de geração de energia para a produção, central ao projeto desenvolvimentista dos Estados nacionais, historicamente tem sido detonadora de embates e controvérsias que acionam distintos sistemas de relevâncias e põem em disputa atores em posições de força marcadamente desiguais, reafirmando que nesses enfrentamentos a realidade vivida pelas populações locais diretamente atingidas pelos empreendimentos vem sendo profundamente alterada e suas demandas desconsideradas.

Contudo, os autores trazem uma contribuição singular ao debate: seu foco são os moradores ribeirinhos que residem à jusante do reservatório e não aqueles que vivem nas áreas a serem inundadas - e que, portanto, precisariam ser desterritorializados. Em pesquisa que conjuga etnografia de documentos (produzidos 
no confronto legal que opôs diferentes instâncias do Estado brasileiro entre si e moradores locais) e pesquisa de campo (entrevistas e observação direta), os ribeirinhos à jusante surgem como "um contingente de atingidos ignorados pelo Estado e pelas empresas do setor elétrico" brasileiros. Afinal, a alteração introduzida pela hidrelétrica em suas vidas é mais sutil, realiza-se na alteração do regime de vazão do rio fundamental para a reprodução de um modo de vida camponês que requer um fino ajustamento entre espaço, disponibilidade de água e atividade produtiva, ou seja, cuja sobrevivência requer a complementaridade entre produção no período das chuvas (roças) e produção baseada na vazante do rio durante a estiagem (hortas). Justamente esta sazonalidade é alterada na medida em que a vazante do rio Jequitinhonha tornou-se instável pelo manejo do subir e descer das águas feito pelos operadores da barragem, a paisagem tornou-se "imprevisível” e a própria matriz que organiza a vida camponesa vê-se ameaçada.

A esta insegurança soma-se o temor da qualidade da própria água que, ao ser represada e passar pelas turbinas da hidrelétrica, parece adquirir características estranhas à natureza e nocivas à vida. Embora os moradores assinalem sua deterioração e rejeitem esta água, são obrigados a usá-la por falta de alternativa, por não terem serviços de abastecimento de água tratada para consumo humano. É desta perspectiva que os autores apontam para o duplo registro de insegurança (Scott, 2009) aos quais os ribeirinhos à jusante estão expostos: uma exclusão permanente própria do modelo de desenvolvimento brasileiro ("insegurança estrutural”) e a exclusão específica oriunda da mudança de vazão do rio (“insegurança administrada") - sendo esta condição agravada pelo não reconhecimento desta população como atingida pela barragem e, portanto, como não beneficiária de políticas de compensação ou ressarcimento.

O artigo seguinte, "Relevâncias da experiência e critérios de potabilidade: conflito de interpretações sobre a água 'boa' em uma localidade do Cariri”, de Carla Teixeira, Luís Cláudio Moura e Anna Davison, também aborda a ação do Estado brasileiro no que concerne ao principal manancial de água de uma pequena localidade, com cerca de 4 mil habitantes, no sertão nordestino. Diferente do Vale do Jequitinhonha (que também integra a área do polígono da seca), na cidade de Granjeiro (Ceará) trata-se do desenvolvimento de uma política de governo implantada na primeira metade dos anos 2000, cujo objetivo era fornecer água potável às residências. Para tal, a escolha técnica foi o tratamento das águas do Açude do Junco e sua canalização até a porta de entrada das casas. A pesquisa de campo, contudo, revelou a ineficiência desta política considerada de inclusão social, no vocabulário político democrático, pela recusa dos moradores em utilizarem esta água para consumo humano em prol de outra água também 
disponível no município (a água dos chafarizes), tida como melhor em termos de sabor, aparência e consequências para o corpo, mas cuja qualidade sanitária era duvidosa.

Sem cair na interpretação fácil, mas equivocada, de opor razão técnica universal à lógica sensorial local, os autores mergulharam na hierarquia das águas e investigaram a experiência cotidiana dos moradores com sua diversidade. Levaram a sério o lugar social e moral ocupado pelo Açude na vida granjeirense, os usos diferenciados que os moradores e os políticos dele faziam, o julgamento de maior ou menor adequação desses usos e seus efeitos para a qualidade inferior de suas águas, aferidos pelo mal-estar sentido por aqueles que delas bebiam ou com elas se banhavam. Contrapuseram esta experiência, por um lado, ao reconhecimento que os moradores tinham da eficácia relativa do tratamento pelo qual a água passava antes de chegar aos seus lares e, por outro, à sua própria rejeição (dos pesquisadores) a beber desta água, embora compartilhassem do valor dos procedimentos de produção de potabilidade utilizados no Açude.

Por tal procedimento reflexivo, lograram construir uma compreensão que, ao invés de opor visões de mundo e racionalidades (como estratégia de análise), ou ainda patamares distintos de acesso à informação a serem superados por ações de "educação" (numa perspectiva de intervenção de governo), traçou uma configuração cujas complexidade e fronteiras permeáveis constituíram-se pela consideração dos "engajamentos distintos no mundo" experimentados pelos diferentes atores (moradores, autoridades locais, engenheiros, pesquisadores, educadores etc.). Desta forma, os autores delinearam um horizonte de entendimento em que a verdade técnica da potabilidade não resistia à verdade experimentada no cuidado de si no mundo da vida e, assim, tornaram visíveis os limites da estratégia governamental que está focada na dimensão físico-química da água em nome da promoção do bem-estar da população, bem como as relações de poder que o processo de argumentação técnica engendra ao desqualificar como ignorância os sistemas de relevância e apreensão da água, os quais se constituem por meio das ações cotidianas no mundo. E, por tal articulação, revelaram a importância dos processos de estatização na conformação dos mundos naturalizados analisados pela fenomenologia do mundo social e frequentemente por esta desconsiderados.

Mantendo-se, ainda, nas fronteiras nacionais brasileiras, Carlos Sautchuck nos insere no contexto amazônico da pequena Sucuriju por meio da investigação das relações entre meio hídrico e a existência de dois tipos de pescadores: os laguistas e os costeiros. Em seu artigo "Temporalidades hídricas: fluxos e sinais no estuário do Amazonas”, debruça-se sobre as nuanças locais de sentidos sobre o 
meio hídrico na busca por apreender como as habilidades técnicas emanam do vínculo das pessoas com o meio (a água), reafirmando a perspectiva maussiana de que as relações com o ambiente têm caráter generativo de seres e coisas. Distanciando-se, contudo, da dicotomia recorrente entre espaços terrestre e aquático, o autor nos apresenta a importância que a água encerra para a vila de Sucuriju, sobretudo no que diz respeito especificamente a dois ambientes com propriedades hídricas singulares: o Lago e o Mar. É na abordagem dos sistemas de relações propiciados por estes dois espaços que as formas distintas de pesca se apresentam como técnicas, em sentido não restritivo a funções instrumentais, que permitem encontros diferenciados entre o tempo e o espaço.

No ambiente lacustre, a água se apresenta como "parada" e sua temporalidade perde relevância. A água apreciada é definida como "bonita", ou seja, propícia às percepções mútuas entre laguista e pirarucu, pescador e pesca. Já no ambiente costeiro, a água define-se principalmente pelo seu fluxo intenso, as marés e a pororoca, e suas propriedades evocadas são hidrodinâmicas: a água pode estar "macia”, "quebrar” ou "puxar". Assim, observar o movimento das marés é central para a pesca costeira, exigindo interações físicas entre os corpos. Como destacou o autor, se no lago a água é vivida como uma interface comunicativa entre seres, no mar a água é experimentada como movimento, como um fluxo espaço-temporal. Lá estamos no campo metafórico da semiótica, aqui no da cinética. Se tais interpretações em uma leitura inicial chamam a atenção por sua inspiração conceitual, o texto trata de dar-lhes consistência etnográfica. Sautchuck apresenta delicadamente os elementos que constituem e qualificam os dois tipos de pesca, desdobra-os em várias direções e, assim, convida o leitor a adentrar nestes dois modos de vida. A qualidade de sua pesquisa de campo pode ser apreciada numa escrita que se recusa a resvalar para conclusões elegantes e ambiciosas, mas sem sustentação nos processos, fluxos e ritmos em ação na conexão entre pescadores e ambiente.

Os artigos de Cristiana Bastos e Maria Manuel Quintela, ambas com amplo domínio neste campo de investigação, trazem para o debate as águas termais. Embora os textos guardem pontos de convergência significativos, constituem-se a partir de recortes etnográficos distintos e ênfases reflexivas singulares.

Em "Banhos de princesas e de lázaros: termalismo e estratificação social”, Bastos aborda o termalismo europeu articulando fontes diversas (romances, trabalhos de historiadores, sociólogos, antropólogos etc.) e pesquisa de campo própria em Monchique (Portugal). Seu argumento central é analisar como o leque social amplo daqueles que frequentam as estações termais, bem como a convivência entre glamour e tratamento de leprosos, sifilíticos e paralíticos não 
constituem um paradoxo a ser explicado. Ao contrário, seria tal diversidade, ou em suas palavras, o "convívio de diferentes e diferenças", o núcleo responsável pelo sucesso e a longevidade do termalismo europeu. Como na referência que faz a Maupassant, é a cura-espetáculo de um paralítico que garante a verdade das águas que curam, reforçando, assim, o prestígio do lugar, a ampliação da clientela e dos lucros.

Não há, portanto, contradição ou ambiguidade entre as duas vertentes do termalismo (luxo e tratamento), o que há é uma relação de reforço mútuo, na qual o tratar e o lazer se combinam e se traduzem em eficácia material e simbólica própria do valor central do termalismo europeu de que há "água para todos, para tudo tratar, mas a todos de modos diferentes, cada um no seu lugar". Se em determinado momento a moderna hidrologia, com seu ethos médico e legitimada pela participação estatal em diferentes contextos nacionais europeus, pareceu romper esta complementaridade, a autora nos conduz em suas últimas páginas às novas experiências termais que vêm a atualizar os prazeres das águas suscitados pela exploração dos sentidos e os combinam com outras experiências de consumo e estilos de vida contemporâneos. Com habilidade narrativa, Bastos sustenta seu fio reflexivo e tece um texto que, sendo panorâmico, permanece ancorado nas singularidades do mundo vivido.

Maria Manuel Quintela em "Curar e recrear em águas termais: um diálogo etnográfico entre Portugal (Termas de São Pedro do Sul e Termas da Sulfúrea) e Brasil (Caldas de Imperatriz)", como o título do artigo já expressa, desenvolve suas reflexões por caminhos distintos. Focalizada em contextos etnográficos estritos, a autora realiza a ambição de uma análise comparativa que permite traçar tendências afins e contrastantes entre Portugal e Brasil ao tomar como eixo articulador a relação do termalismo com os sistemas médicos em que se inserem. A depender da forma como o termalismo é considerado, seja como parte do "aparelho biomédico" (Portugal) ou como "prática complementar" apenas recentemente reconhecida (Brasil), a água estrutura-se de maneira diferente como experiência que simultaneamente cura e recreia.

Desta perspectiva, a autora põe em diálogo, no eixo teórico, a literatura sobre instituições hospitalares e a literatura sobre instituições de lazer e turismo e, no eixo etnográfico, aborda as características próprias de cada estação termal e as triangula com os eixos analíticos acima referidos. Ao longo de tal empreendimento, argumenta ser a conjugação inusitada entre organização de atividades de sociabilidade facilitadoras do prazer (próprias das instituições de lazer) e de atividades nas quais o indivíduo é separado do mundo social para tratar-se (próprias das instituições hospitalares) que define a especificidade das 
estações termais em geral. Contudo, é a consideração dos sistemas médicos que permite a compreensão da qualidade distintiva entre estações termais portuguesas e brasileiras: se as primeiras requerem prescrição médica e não dispõem de hospedagem no local dos banhos, as segundas são estruturadas como hotéis, não sendo, portanto, reguladas medicamente e podendo ser vividas como escolhas individuais de produção de bem-estar, embora em ambas as "memórias balneares" expressem, em meio à diversidade de atores sociais e de motivações, a coexistência, por vezes tensa, de atividades terapêuticas e recreativas. Afinal, nas palavras de Quintela, "Não é esta a especificidade da prática terapêutica termal, que a recreação é um dos elementos da eficácia simbólica da cura?”.

Com o texto de Geneviève Bédoucha voltamos ao universo da pesca, mas agora em contexto etnográfico totalmente diverso: a exploração da piscicultura em tanques em Brenne (França). A reflexão que tal realidade suscita à autora neste artigo remete à gestão da água e seu valor em um ambiente de "abundância”, como o é a zona úmida francesa em que a cidade se localiza. Assim, por um percurso de pesquisa que combina abrangência etnográfica e histórica com profundidade de pesquisa de campo, em "Rare ou abondante, l'eau précieuse. En France, l'exemple de la Brenne dês étangs”, Bédoucha discute a construção social das noções de abundância e escassez de água argumentando que se a raridade da água não impede o desperdício (da perspectiva de observadores externos), tampouco sua fartura resultaria na desconsideração da água como algo precioso (da perspectiva dos sujeitos com ela engajados). Este é o caráter da água em Brenne, cujo valor central é não desperdiçar água, segundo uma ética que também não permite recusá-la a ninguém.

Ao abordar este "mundo dos tanques", a autora descreve densamente as implicações políticas, simbólicas e econômicas da técnica de vazar a água de um tanque para o seguinte, do superior para o localizado abaixo, de modo a permitir um equilíbrio entre a água que sai e entra de um para o outro e, assim, possibilitar a pesca nos tanques que devem estar suficientemente esvaziados para que os peixes se concentrem num círculo de água reduzido (facilitando sua captura), mas não em excesso para evitar a baixa oxigenação da água. Semelhante interdependência entre tanques não pertencentes aos mesmos proprietários ou arrendatários engendra uma tensão permanente, que envolve também os agricultores e os criadores que utilizam as terras contínuas, mas também transforma a água em uma linguagem privilegiada: a água liga estreitamente as pessoas, é finalidade em si e meio que estrutura as relações sociais, enfim, um capital que não se esgota na razão econômica da exploração da piscicultura, mas possui valor afetivo, perpetua e atribui prestígio e poder aos que a "possuem". 
Na sequência temos o artigo "Community water management. Is it still possible? Anthropological perspectives”. De autoria de Toufik Ftaïta, o trabalho aborda as sociedades de oásis do norte da África, mais especificamente no Marrocos. Seu foco, contudo, não é a forma como estas sociedades têm garantido sua existência por meio de um manejo da água baseado em sua organização tradicional. Ftaïta investiga o processo de transformação vivido pelas comunidades locais de oásis atravessadas por dimensões políticas, econômicas e ambientais que extrapolam suas fronteiras e envolvem agendas global e nacional. Para tal, após apresentar os três momentos históricos distintos de manejo da irrigação no Marrocos, contrasta dois modelos de governança da água: o modelo tradicional de base comunitária (sociedades oasianas) e o modelo associativista e participativo moderno (política do governo marroquino), buscando apontar os limites de tradução entre ambos.

Com esta mirada, o autor traça o enfraquecimento dos modelos tradicionais (propriedade individual dos direitos sobre a água e propriedade coletiva das instalações hidráulicas) que, numa matriz hierárquica, tem sido localmente propício a negociações políticas e sociais na resolução de suas tensões, em prol de um modelo individualista universal, de matriz igualitária, que legalmente se ampara na categoria de "usuários da água" e os convoca a criar associações de modo a "participarem" do manejo das redes de irrigação e "contribuírem" para os seus custos de manutenção e reparo. Os desdobramentos desta ingerência do Estado nas relações entre os agricultores de irrigação são referenciados tanto ao contexto internacional dos "ajustes estruturais" observados em diferentes contextos nacionais africanos, como às possibilidades e aos problemas da adesão dos agricultores marroquinos a um ou a outro modelo. Ao fim deste percurso, Ftaïta retoma a questão-chave do acesso à água nas sociedades oasianas nos moldes das instituições tradicionais e nos termos da modernização legal, política e econômica em curso no norte da África para avançar na compreensão do que vem sendo proposto como "boa governança" da água nesta região.

"Representing water: visual anthropology and divergent trajectories in human environmental relations", de Veronica Strang, encerra este dossiê. Trata-se de um texto que tem como foco a conexão entre mudanças cosmológicas e materiais e integra um projeto mais amplo que busca processos de longa duração, considerando-os em perspectiva comparada e articulando diferentes fontes disciplinares. Assim, se insere na ambição de, por meio de uma análise sistemática temporal e espacial da imagética da água, traçar trajetórias das relações entre seres humanos e ambientes. Seu objetivo é destacar transformações-chave que levaram a divergências de percurso, a crenças, valores e práticas diversas que 
subjazem conflitos contemporâneos em torno da água.

Tomando como referência etnográfica neste artigo Austrália e Nova Zelândia, Strang constrói sua hipótese de que uma transformação-chave ocorreu na mudança histórica desencadeada pelo processo colonial em que as cosmologias naturais perderam espaço para as cosmologias humanizadas. Nesse processo de desespiritualização do ambiente teria havido uma mudança crítica na balança de poder envolvendo os seres humanos e seus ambientes: a perspectiva colaborativa entre diferentes forças da natureza na conformação do meio cedeu lugar à agência espiritual humanizada e, assim, abriu caminho para práticas materiais e formas de uso de "recursos" mais diretivas. Ciente do desafio metodológico desta empreitada, a autora referencia mutuamente três eixos de investigação considerando seus contextos específicos: crenças e valores cosmológicos; engajamentos materiais com a água; representações visuais da água e de seus seres. No contexto empírico em foco, Strang rastreia as transformações nas imagens da Rainbow Serpent (Austrália) e do Taniwha (Nova Zelândia), insere-as nos seus respectivos contextos cosmológico e político-histórico, verifica as mudanças ocorridas nos usos materiais da água e busca compreender em que medida tais alterações estruturam a forma como os povos aborígenes encaminham suas lutas políticas relativas ao ambiente nos diferentes contextos nacionais em que se inserem.

Gostaríamos de encerrar esta apresentação lembrando que Franz Boas, na sua tese de doutoramento, observou que cada um via as cores da água de forma diversa, cada olho, cada cor, cada água. E essa constatação levou-o a estudar antropologia e a apostar no olhar da diversidade cultural. Ou seja, a natureza e a cultura cruzaram-se. Também aqui temos diversos olhares e cores da água. Pelos artigos apresentados, o leitor poderá ver que os estudos etnográficos permanecem a acrescentar novas abordagens e criatividade sobre os contextos estudados e, de acordo com cada um, assim são as preocupações com políticas públicas, em que se destacam os eixos espaço-tempo, história, lazer, saúde, profissões, disciplinas, políticas públicas, corpos e sentidos. 


\section{Referências bibliográficas}

ANDERSON, Susan \& TABB, Bruce. 2002 Water, Leisure \& Culture: European Historical Perspectives. Oxford: Berg.

BACHELARD, Gaston. 1942. L'eau et les rêves. Essai sur l'imagination de la matière. Paris: Librairie José Corti.

BASTOS, Cristiana. 2003. "Comentário: Antropologias saindo da água”. Etnográfica, 7(1): 3-12 . . (coord.). 2003. “Usos Sociais da água”. Etnográfica, 7(1).

BASTOS, Cristiana; QUINTELA, Maria Manuel \& PERESTRELO, António. 2006. “O Novo Aquilégio”. ICS-UL. Disponível em: www.aguas.ics.ul.pt. Acesso em: 03 /09/.012 CORBIN, Alain. 1986 [1982]. Le Miasme et la Junquille. Paris: Flammarion.

CRESSIER, Patrice (dir.). 2006. La maîtrise de l'eau en al-Andalus: Paysages, pratiques et techniques. Madrid: Casa de Velasquez.

DURAND, Jean-Yves. 1996. “O Hidrogeólogo, o Vedor de Água, o Etnógrafo e algumas das suas 'Técnicas do Corpo'. In: Miguel Vale de Almeida (org.). Corpo Presente: Treze Reflexões Antropológicas sobre o Corpo. Oeiras: Celta Editora. pp. 87-103.

2003. "A Diluição do Consenso: A Água, de 'Fonte de Vida' a 'Património Colectivo’. Etnográfica, 7 (1): 15-31.

ELIADE, Mircea, 1994 [1949]. “As Águas e o Simbolismo Aquático”. In: Tratado das Religiões. Lisboa: ASA. pp. 243-275.

ELIAS, Norbert. 1976 [1969]. La Civilization des Moeurs. Paris: Calmann-Lévy.

FELDHAUSS, Anne. 1995. Water \& Womanhood. Oxford: Oxford University Press.

FTAITA, Toufik. 2006. Anthropologie de l'irrigation les Oasis de Tiznit Maroc. Paris: L'Harmattan.

GOUBERT, Jean-Pierre. 1986. La conquête de l'eau. Paris: Robert-Lafond.

HIDIROGLOU, Patricia. 1994. L'Eau Divine et sa Symbolique. Paris: Editions Albin Michel. HIPOCRATE. 1996. Airs, eaux, lieux, Paris: Editions Payots \& Rivages.

KAPLAN, M. 2007. "Fijian Water in Fiji and New York: local politics and a global commodity”. Cultural Anthropology, 22 (4): 685-776. 
2011. "Lonely drinking fountains and comforting coolers: paradoxes of water value and ironies of water use”. Cultural Anthropology, 26 (4): 514-41

MARRAS, Stelio. 2003. A propósito de Águas Virtuosas. Formação e ocorrências de uma estação balneária no Brasil. Poços de Caldas: Editora UFMG.

MARTEL, Claude. 1989. “L'eau dans tous ses états”. Terrain, 13: 110-116.

ORLOVE, Ben \& CATON, Steven C. 2010. "Water sustainability: anthropological approaches and prospects”. Ann. Rev. of Anthropology, 39: 401-415.

QUINTELA, Maria Manuel. 2001. “Turismo e Reumatismo: Etnografia de uma Prática Terapêutica nas Termas de São Pedro do Sul”. Etnográfica, 5 (2): 359-374. . 2004. "Práticas e Saberes Termais em Portugal e no Brasil". História, Ciências, Saúde-Manguinhos, v. 11, supl. 1, pp. 239-260.

ROCHE, Daniel. 1998. História das Coisas Banais: Nascimento do Consumo nas Sociedades Tradicionais, Sécs. XVII-XIX. Lisboa: Teorema.

SANT’ANA, Denise. 2007. Cidade das águas. Usos de rios, córregos, bicas e chafarizes em São Paulo (1822-1901). São Paulo: Senac.

SANTOS, Silvio Coelho. 2003. "A geração hídrica de Electricidade no sul do Brasil e seus impactos sociais”. Etnográfica, 7(1): 87-103.

SARAIVA, Clara. 2007. "Um museu debaixo de água: o caso da luz". Etnográfica, 11(2): 441-470.

SCHAMA, Simon. 1996. Paisagem e Memória. São Paulo: Companhia das Letras.

SCHNEIER-MADANES, Graciela (dir.). 2010. La Mondialization de l'eau. La governance en question. Paris: La Découverte.

STERN, Henri. 2003. "Anupam Mishra, Traditions de l'eau dans le désert indien (Les gouttes de lumière du Rajasthan)”. L'Homme, 166, avril-juin.

STRANG, Veronica. 2004. The Meaning of Water. Oxford: Berg. . 2006. "Fluidscapes: water, identity and the senses: introduction". Worldviews: global religions, culture and ecology, 10(2):147-154.

VIGARELlO, Georges. 1988 [1985]. O Limpo e o Sujo: A Higiene do Corpo desde a Idade Média. Lisboa: Editorial Fragmentos.

WATEAU, Fabienne. 2000. Conflitos e Água de Rega: Ensaio sobre a Organização Social no Vale de Melgaço. Lisboa: Dom Quixote. 
2002. “Object et ordre social. D'une canne de roseau à mesurer l'eau aux príncipes de fontionnement d'une communauté rurale portuguaise”. Terrain, 37: 153-161. 2010. "Contester un barrage. Anthropologie d'un processus de gestion social à Alqueva (Portugal). In: Graciela Schneier-Madanes (dir.). La Mondialization de l'eau. La governance en question. Paris: La Découverte.

WATEAU, Fabienne \& CRESSIER, Patrice (orgs.). 2006. Le partage de l'eau (Espagne, Portugal, Maroc). 2. ed. Mélanges de la Casa de Velasquez, v. 36. Madri: Casa de Velazquez. 